Article

\title{
Research on the Mechanical, Thermal, Induction Heating and Healing Properties of Steel Slag/Steel Fibers Composite Asphalt Mixture
}

\author{
Quantao Liu ${ }^{1,2}$, Bin $i^{1}$, Erik Schlangen ${ }^{3, *}$, Yihan Sun ${ }^{4}$ and Shaopeng $\mathrm{Wu}^{1, *}$ \\ 1 State Key Laboratory of Silicate Materials for Architectures, Wuhan University of Technology, \\ Luoshi Road 122, Wuhan 430070, China; liuqt@whut.edu.cn (Q.L.); lib9009@163.com (B.L.) \\ 2 Key Laboratory for Highway Engineering in Special Regions of the Education Ministry of China, Chang'an \\ University, Xi'an 710064, China \\ 3 Faculty of Civil Engineering and Geosciences, Micromechanics Laboratory, Delft University of Technology, \\ Stevinweg 1, 2628 CN Delft, The Netherlands \\ 4 Zhejiang Provincial Institute of Communications Planning, Design \& Research, Hangzhou 310015, China; \\ sunyh@whut.edu.cn \\ * Correspondence: erik.schlangen@tudelft.nl (E.S.); wusp@whut.edu.cn (S.W.); \\ Tel.: +31-15-278-6535 (E.S.); +86-1380-717-6062 (S.W.)
}

Received: 13 September 2017; Accepted: 4 October 2017; Published: 20 October 2017

\begin{abstract}
In this paper, steel slag/steel fiber composite asphalt mixture were prepared. The effects of the addition of steel slag and/or steel fibers on the mechanical, thermal, induction heating and healing properties of asphalt mixture were investigated. The results showed that adding steel slag and/or steel fibers improves the water stability, particle loss resistance and fracture energy of asphalt mixtures. The addition of steel fibers increased the thermal conductivity and thermal diffusion of the asphalt mixture, and steel slag showed a reverse effect. Steel slag asphalt mixture cooled more slowly than steel fiber asphalt mixture, which is beneficial to crack healing of asphalt mixture. The composite of steel fibers and steel slag can enhance the induction heating speed, heating homogeneity and thus enhance the induction healing ratio of asphalt mixture. It is concluded that steel slag/steel fibers composite asphalt mixture achieves good mechanical and induction healing properties.
\end{abstract}

Keywords: asphalt mixture; steel fiber; steel slag; induction heating; healing

\section{Introduction}

Asphalt concrete is a self-healing material which can close micro cracks during rest periods through bitumen flow and diffusion [1]. The potential benefits of applying self healing technology to asphalt pavements include reduced road maintenance with a subsequent reduction in $\mathrm{CO}_{2}$ production, improved safety for both road users and road workers, improved road life span, and reduced cost of road maintenance [2]. However, the healing rate is quite slow due to limited bitumen flow at ambient temperatures. As a temperature sensitive material, the self-healing capacity of asphalt concrete can be enhanced by increasing the ability of wetting and diffusion of asphalt molecules through heating [3]. For this reason, an advanced self-healing technology named induction healing was developed to enhance the self-healing capacity of asphalt concrete through induction heating [4-6]. Steel fibers were added to the asphalt mixture to make it electrically conductive and induction heating was applied to increase the healing capacity of asphalt concrete when cracks occurred in asphalt mastic [7-10]. During induction heating, the asphalt mastic containing steel fibers was heated very quickly while the mineral aggregates could not be heated [10]. In such a way, the cracks within asphalt mastic can be healed quickly without affecting the stone structure. It has been proven by many researchers that induction heating can restore the stiffness, strength and fatigue life and prevent the raveling and cracking of 
asphalt concrete efficiently without ageing asphalt binder due to very short heating time [10-18]. Therefore, induction healing is a promising maintenance technology for asphalt pavement, which can heal the microcracks and prevent them from developing into cracking, stone loss and potholes.

However, the induction heating speed of asphalt mixture is limited. Sun et al. prepared asphalt concrete by replacing mineral aggregates with steel slag and found that it can be heated at $11.6^{\circ} \mathrm{C} / \mathrm{min}$ with induction heating [11]. He et al. prepared asphalt mixture by adding $4 \%$ steel shots and found that its induction heating speed is $33.8^{\circ} \mathrm{C} / \mathrm{min}$ [15]. Liu et al. prepared conductive asphalt concrete by adding $8 \%$ steel wool fibers (by volume of bitumen) and its induction heating was $43.8^{\circ} \mathrm{C} / \mathrm{min}$ [16]. Norambuena-Contreras also prepared conductive asphalt concrete by adding $8 \%$ steel wool fibers and its induction heating was $38.1^{\circ} \mathrm{C} / \mathrm{min}$ [17]. Garcia prepared asphalt concrete by adding $6 \%$ coarse steel fibers and its induction heating was $62.0^{\circ} \mathrm{C} / \mathrm{min}$ [18]. In the aforementioned research, the induction heating speeds of the asphalt mixtures designed still need to be improved to allow fast onsite healing on asphalt pavement.

In this paper, steel slag and steel fiber composite asphalt mixture was prepared to enhance the induction heating speed and healing efficiency. Asphalt mixtures containing steel fiber or steel slag were also prepared for comparison. The water stability, mechanical properties, thermal parameters, heating/cooling characteristics, and healing ratios of different asphalt mixtures were studied.

\section{Materials and Test Methods}

\subsection{Materials}

70\# Base bitumen (SK Corporation, Seoul, South Korea), basalt aggregates (Jinshan Songhe Aggregates Company, Yidu, China), limestone filler (Maliang Aggregates, Jinmen, China), steel slag and steel fibers were used in this research to produce different asphalt mixtures. The basic properties of the bitumen tested according to Chinese Standard test method of bitumen (JTG E20-2011) are shown in Table 1. The specific gravity of coarse and fine aggregates used in this paper is $2.951 \mathrm{~g} / \mathrm{cm}^{3}$ and $2.877 \mathrm{~g} / \mathrm{cm}^{3}$ respectively.

Table 1. Properties of $70^{\#}$ base bitumen.

\begin{tabular}{ccc}
\hline Properties & Results & Technique Index \\
\hline Penetration $\left(25^{\circ} \mathrm{C}, 100 \mathrm{~g}, 5 \mathrm{~s}\right)(0.1 \mathrm{~mm})$ & 62.3 & $60-80$ \\
Softening point $($ ring \& ball $)\left({ }^{\circ} \mathrm{C}\right)$ & 47.8 & $44-54$ \\
Ductility $\left(5 \mathrm{~cm} / \mathrm{min}, 15^{\circ} \mathrm{C}\right)(\mathrm{cm})$ & $>100$ & $\geq 100$ \\
Density $\left(\mathrm{g} / \mathrm{cm}^{3}\right)$ & 1.034 & - \\
\hline
\end{tabular}

Steel slag and steel fibers were used as conductive materials in this paper. Steel slag was used to replace coarse aggregates partially. The steel slag used was produced by Wuhan Iron industry (Wuhan, China). The test method of coarse aggregate was used to evaluate the properties of steel slag. The specific gravity of steel slag was $3.396 \mathrm{~g} / \mathrm{cm}^{3}$, and the water absorption was $3.26 \%$. The Los Angeles abrasion and crush values of steel slag were $12.6 \%$ and $13.5 \%$ respectively. Chinese standard test method for effect of water on bituminous coated aggregate using boiling water $\left(80^{\circ} \mathrm{C}\right.$ and $30 \mathrm{~min}$, similar to AASHTO Guide) was used to determine the adhesion property between asphalt and steel slag, and the adhesion grade of asphalt and steel slag was 5, which is the best adhesion grade in the Chinese specification. Steel fiber used in this paper was produced by Shanghai Odika metal materials company (Shanghai, China). The equivalent diameter of steel fibers ranged from $70 \mu \mathrm{m}$ to $130 \mu \mathrm{m}$ and the average length was $4.2 \mathrm{~mm}$. The recommended steel fiber content $6.0 \%$ (by volume of bitumen) was used in this research [19]. 


\subsection{Gradation Design and Specimen Preparation}

A dense asphalt mixture AC-13 was used in this research, and the gradation curves were shown in Figure 1. Two different gradations were used in Figure 1, where BA means basalt asphalt mixture and SS means basalt mixture modified with steel slag. SS asphalt mixture was made by replacing the coarse aggregates with size 9.5-13.2 mm in BA with steel slag (steel slag in other sizes was not available in the laboratory for the time being). Steel slag has different specific gravity from basalt aggregate, thus the coarse basalt aggregates were replaced by steel slag with the same volume. Another two kinds of self-healing asphalt mixtures (SF (steel fibers) and SF + SS) were obtained by adding $6 \%$ steel fibers (by volume of bitumen) to BA and SS mixtures.

The optimum asphalt-aggregate ratio of BA determined using Marshall Mix design method was $4.8 \%$. The optimal asphalt-aggregate ratio of SF, SS and SF + SS were 5.0\%, $4.9 \%$ and $5.1 \%$ [20]. The volume indices of the four asphalt mixtures were tested and calculated according to Chinese standard and shown in Table 2. According to the gradation results, Marshall Specimens were prepared for further tests. Marshall Specimens used for all tests had similar air voids content (difference less than $1 \%)$ to avoid its effect on properties of asphalt mixtures.

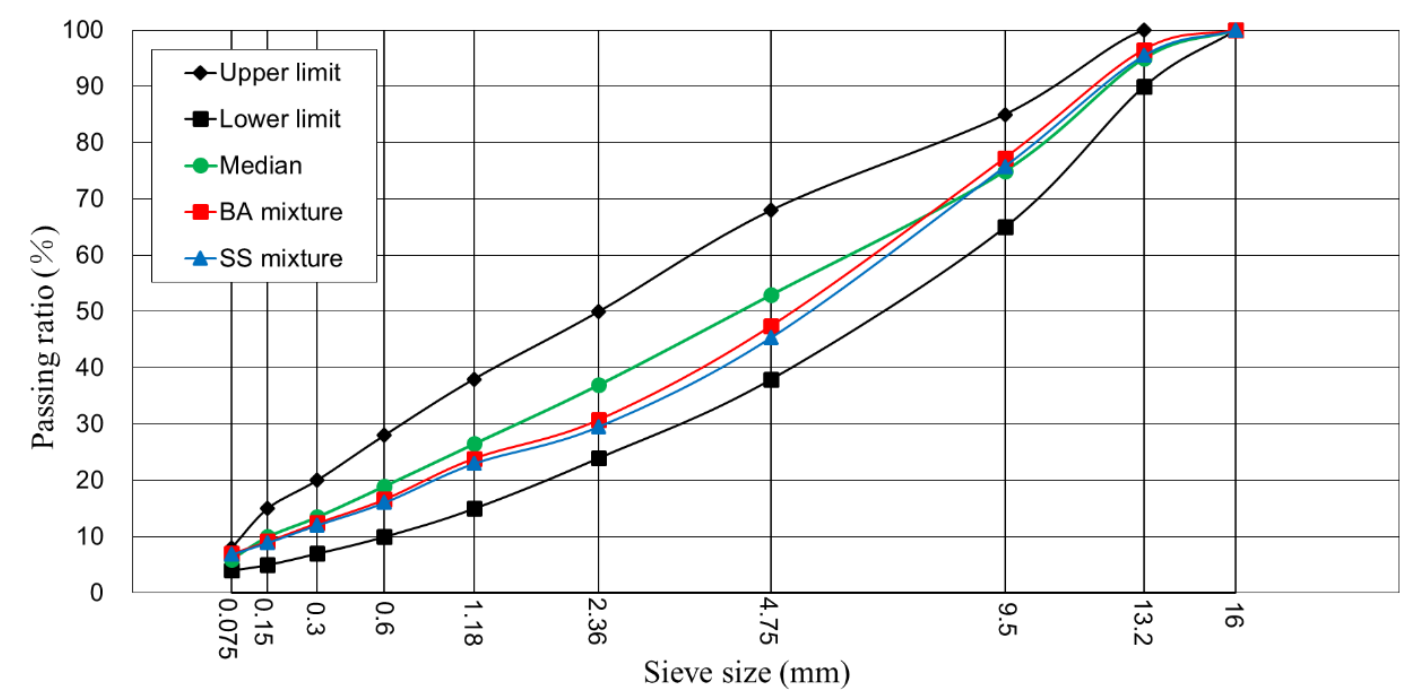

Figure 1. Gradation curves of basalt asphalt (BA) and steel slag (SS) mixture.

Table 2. Compaction levels and mix design parameters. BA: basalt asphalt; SF: steel fibers; SS: steel slag.

\begin{tabular}{ccccc}
\hline Mixture types & BA & SF & SS & SF + SS \\
\hline Optimum asphalt content /\% & 4.8 & 5.0 & 4.9 & 5.1 \\
Air voids /\% & 3.53 & 4.36 & 3.79 & 4.25 \\
Voids in mineral aggregates /\% & 14.9 & 14.3 & 14.1 & 13.5 \\
Voids filled with asphalt /\% & 76.3 & 69.4 & 73.4 & 68.6 \\
\hline
\end{tabular}

In this paper, semi-circle samples were used to study the fracture energy and healing ratios of different asphalt mixtures. The failure form of semi-circular bending (SCB) test is tensile failure, avoiding other types of damage on samples. Therefore, SCB test is usually used to analyze and evaluate the fracture properties of asphalt mixtures [21]. All SCB samples were cut from Marshall Samples with a thickness of $30 \mathrm{~mm}$ and a notch of $20 \mathrm{~mm}$ in the middle of the radial direction. The samples used for heating and healing tests were the same as SCB samples. The samples for thermal parameters test were cut from Marshall Specimens with diameter $100 \mathrm{~mm}$ and height $30 \mathrm{~mm}$. 


\subsection{Moisture Susceptibility Test}

The water susceptibility of asphalt mixture is directly related to the durability of asphalt pavement. Thus, there is need to study the effect of steel fiber and steel slag on the moisture resistance of asphalt mixture. The moisture susceptibility of the mixtures studied was evaluated by moisture indices using Marshall Stability Ratio (MSR) for different kinds of specimens following ASTM D1559 standard method. The MSR was calculated according to Equation (1).

$$
M S R=\frac{M_{s}}{M_{\mathrm{o}}} \times 100
$$

Where:

$M_{s}$ : the average stability of specimens which were placed into the water at $60^{\circ} \mathrm{C}$ for $48 \mathrm{~h}$;

$M_{o}$ : the average stability of specimens which were placed into the water at $60^{\circ} \mathrm{C}$ for $30 \mathrm{~min}$.

\subsection{Cantabro Test}

The adhesion property between asphalt and steel fiber or steel slag has a great impact on mechanical properties of asphalt mixture. Therefore, it is necessary to investigate the adhesion properties of four asphalt mixtures. In this paper, the particle loss values of Marshall Samples with steel fiber or steel slag were measured in standard Cantabro test. The tests were carried at $20{ }^{\circ} \mathrm{C}$ in a Los Angeles abrasion machine without steel balls according to the Chinese standard test method (JTG E20-2011 T0733-2011). The weight loss ratio, which is calculated according to Equation (2), is an indication of anti-loosening capacity of the asphalt mixture. Lower ratio means better adhesion between asphalt with steel fiber and steel slag.

$$
P L=\frac{W_{1}-W_{2}}{W_{1}} \times 100
$$

Where:

$P L:$ the particle loss ratio (\%);

$W_{1}$ : the weight of original samples;

$W_{2}$ : the residual weight of test samples.

\subsection{Semi-Circle Bending Fracture Test}

Fracture energy is an important indicator to characterize the cracking resistance of asphalt mixture and post-cracking energy can be used to characterize the ductility of asphalt mixture [22]. A constant displacement of $50 \mathrm{~mm} / \mathrm{min}$ was applied to the samples with Universal Testing Machine (UTM-25) until the samples were totally broken into two pieces to obtain the force-displacement curves. According to the RILEM TC50-FMC specification [23], fracture energy and post-cracking energy of the samples were calculated from the curves to evaluate the mechanical properties of different asphalt mixtures. The fracture energy and post-cracking energy $G_{f}$ was calculated as Equation (3).

$$
G_{f}=\frac{W_{0}+m g \delta_{0}}{A_{l i g}}
$$

Where:

$W_{0}$ : The area below the measured load force-displacement curve at 0 to peak force for fracture energy and peak force to end of line for post-cracking energy;

$m$ : Weight of the specimen; $g: 9.81 \mathrm{~m} / \mathrm{s}^{2}$;

$\delta_{0}$ : Deformation at 0 to peak force for fracture energy and peak force to end of line for post-cracking energy; 
$A_{\text {lig: }}$ Area of ligament (product of ligament length and thickness of a specimen)

\subsection{Thermal Constants Test}

Thermal conductivity is one of the important parameters that influences the heating and cooling efficiency of asphalt mixture. The heat delivered to surface is increased by using high thermal conductive asphalt mixture. In addition, thermal diffusivity of the asphalt mixture determines how rapidly the heat can transfer from inner to the surface. Asphalt mixture with a lower thermal diffusivity can maintain the temperature for a longer time. Hench, accurate determination of thermal properties of asphalt mixtures containing steel fiber or/and steel slag are essential for the heating/cooling and healing analysis.

The thermal constants of asphalt mixtures were measured by a Hot Disk Thermal Analyzer (TPS 2500S, Hot Disk, Göteborg, Sweden). The thermal conductivity $k$ and diffusion $\alpha$ can be directly obtained and the volumetric heat capacity was calculated by Equation (4). The selected probe radius is $14.61 \mathrm{~mm}$, heating time is $80 \mathrm{~s}$ and the test power is $350 \mathrm{mw}$.

$$
k=\alpha \cdot c_{p}
$$

Where:

$k$ :thermal conductivity, $\mathrm{W} /(\mathrm{m} \cdot \mathrm{K})$;

$\alpha$ : thermal diffusion, $\left(\mathrm{mm}^{2} / \mathrm{s}\right)$;

$c_{p}$ : volumetric heat capacity, $\mathrm{MJ} /\left(\mathrm{m}^{3} \cdot \mathrm{K}\right)$.

As shown in Figure 2, the pieces of the Marshall sample were in contact with the two surfaces of the probe, which is connected to the thermal constant analyzer. The probes cannot completely cover all aggregate and mortar, thus the thermal constant results may be unrepresentative. Therefore, it is necessary to increase the test times to reduce data bias. Four regions of the center of the sample were chosen for thermal test and each point was tested for 3 times. The average of 12 test results was used to characterize the thermal property of each sample. The waiting time between two successive tests was at least $10 \mathrm{~min}$.

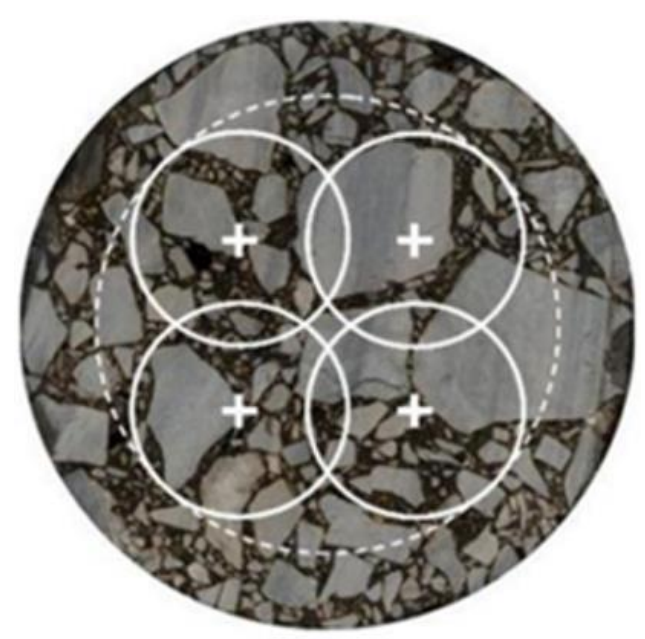

Figure 2. Thermal parameter test points of specimen.

\subsection{Heating and Cooling Characteristics Measurement}

Heating and cooling characteristics of different types of asphalt mixtures can be quite different due to the properties of materials. As BA is not electrically conductive, it cannot be heated with induction energy. Other three asphalt mixtures were heated with an induction heating instrument, 
and the top surface temperatures of the samples during heating process were recorded. The cooling process was also recorded after the top surface temperature of the samples reached $80^{\circ} \mathrm{C}$. The heating and cooling temperature testing system was shown in Figure 3. The output power and frequency of the induction machine was $8.3 \mathrm{kw}$ and $123 \mathrm{kHz}$, and the distance between the coil and the surface of samples was keep at $10 \mathrm{~mm}$, which is a typical heating distance used for onsite heating in the pavement. An infrared camera with pixels of $320 \times 240$ was used to record the surface temperature of samples during the whole test. The average temperatures at the top surfaces of the samples were calculated with the software of the infrared camera.

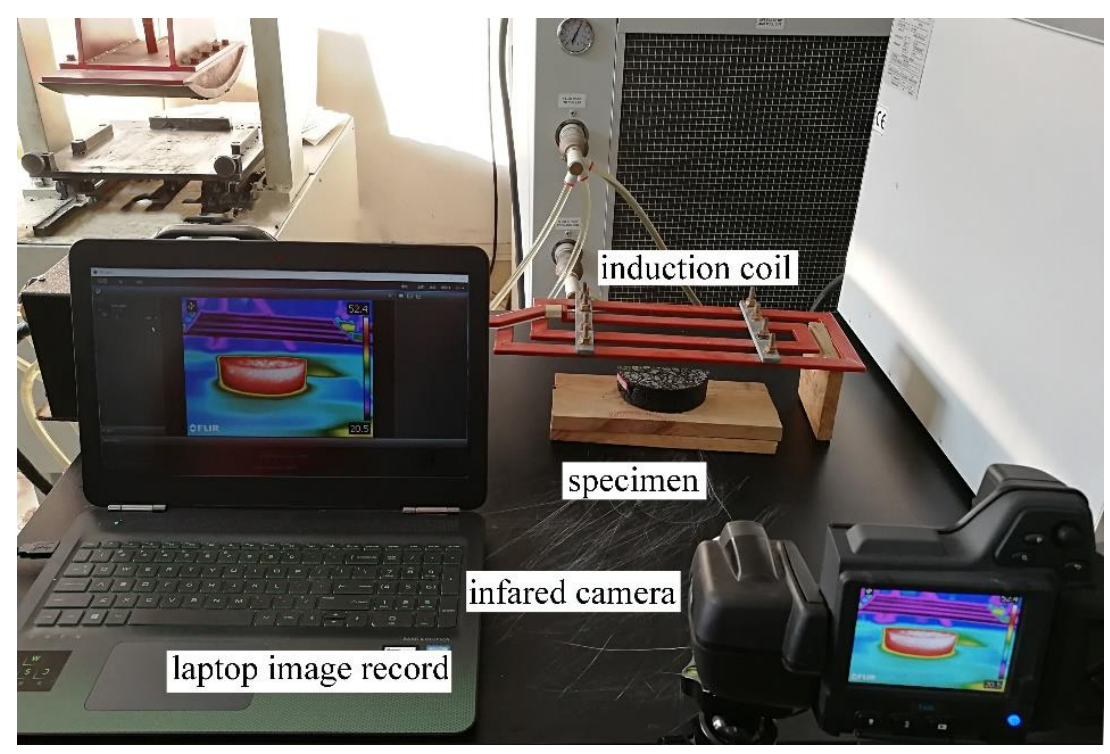

Figure 3. Heating and cooling testing system.

\subsection{Induction-Healing Test}

The healing tests were carried out as follows: (1) Semi-circular specimens were placed in $-10{ }^{\circ} \mathrm{C}$ for at least $4 \mathrm{~h}$, then fractured with three-point bending setup of UTM-25 machine until failure (stopped automatically) and the original broken force $F_{0}$ can be obtained. The loading speed of axis was $50 \mathrm{~mm} / \mathrm{min}$. (2) The broken samples were induction heated to different target temperatures $\left(60^{\circ} \mathrm{C} / 70{ }^{\circ} \mathrm{C} / 80{ }^{\circ} \mathrm{C} / 90^{\circ} \mathrm{C}\right)$ using the heating method described in Section 2.7. After the healing test, the samples were kept at room temperature for $3 \mathrm{~h}$ to cool down. (3) The healed samples were broken again at $-10{ }^{\circ} \mathrm{C}$ as step (1) to get the broken force $F_{1}$ after healing. The healing ratio is calculated as Equation (5):

$$
R=\frac{F_{1}}{F_{0}} \times 100
$$

To avoid overheating and excess expansion of the samples, the maximum heating temperature was set at $90{ }^{\circ} \mathrm{C}$. Induction healing test was not conducted on BA because it cannot be heated and healed with induction heating.

\section{Results and Discussion}

\subsection{Effect of Steel Fibers and Steel Slag on the Moisture Susceptibility of Asphalt Mixture}

The adhesion between aggregate and bitumen is crucial in asphalt pavements and has a strong influence on the moisture susceptibility and service time of the road [24] The stability and moisture susceptibility of four kinds of asphalt mixtures were shown in Figure 4. Compared with BA, the Marshall stability of SF, SS and SF + SS increased by $11.1 \%, 18.4 \%$ and $28.9 \%$ respectively. It means that adding steel fibers or steel slag can improve the high temperature property of asphalt mixture [25] 
and the composite of steel fibers and steel slag shows the best improvement. The samples containing steel fibers or/and steel slag still shows higher stability after moisture damage. The MSR of all mixes satisfied the minimum index of typically standardized value (80\%) for asphalt mixture. The MSR of SF, SS and SF + SS increased by $8.0 \%, 14.7 \%$ and $10.4 \%$ respectively compared with BA, which indicates that the water resistance of asphalt mixture was improved as well by the addition steel fibers or/and steel slag. It can be seen that the residual stability of SS was higher than SF and SF + SS. It can be attributed to two reasons. First, steel slag is alkali and has strong adhesion with asphalt. Second, the SS mixture is a little denser shown in Table 2.

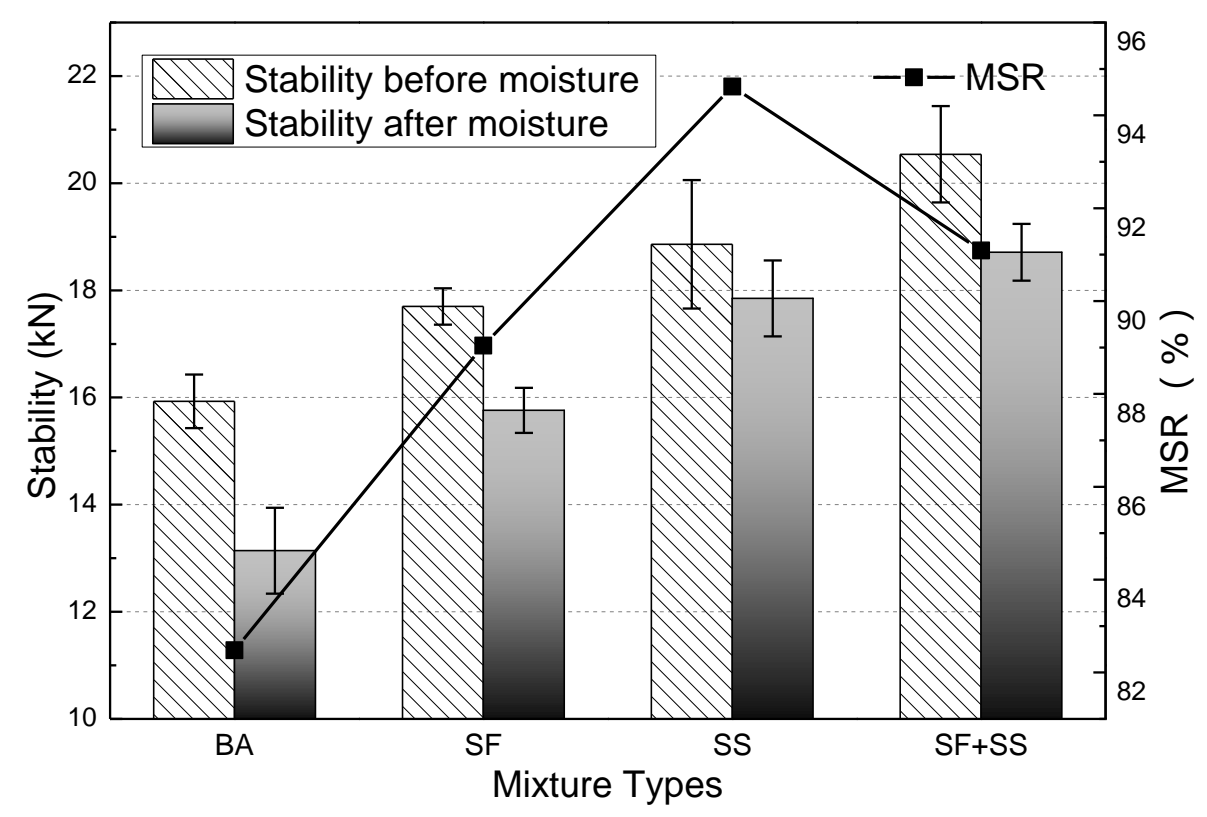

Figure 4. Marshall Stability and Marshall Stability Ratio (MSR) of different asphalt mixtures. SF: steel fibers.

\subsection{Effect of Steel Fibers and Steel Slag on the Particle Loss Resistance of Asphalt Mixture}

It can be seen from Figure 5 that BA has the largest particle loss ratio compared to other three asphalt mixtures, while SF + SS shows the lowest particle loss ratio. Adding steel fibers to asphalt mixture can reduce the particle loss, indicating an improvement of the strength of the mixture. The specific volume characteristics and surface texture structure of steel fibers can improve the absorption and stabilization of asphalt. Furthermore, the spatial network structures formed by steel fibers, which was distributed between the aggregates, has a reinforcing effect on the mixture. The results of $\mathrm{SF}+\mathrm{SS}$ presented the same conclusion that the addition of steel fiber can enhances the cohesion of asphalt mixture.

The addition of steel slag can also decrease the particle loss slightly comparing with BA. The reason for this can be explained by the properties of steel slag which has high wear resistance and porous structure. More asphalt was absorbed resulting the increased bonding area between asphalt and steel slag. Basicity property of steel slag also contribute to good adhesion between asphalt and steel slag, making better wrapping with asphalt [26]. SF + SS has the highest Particle loss resistance due to the reinforcement of steel fibers and the strong adhesion between asphalt and steel slag. 


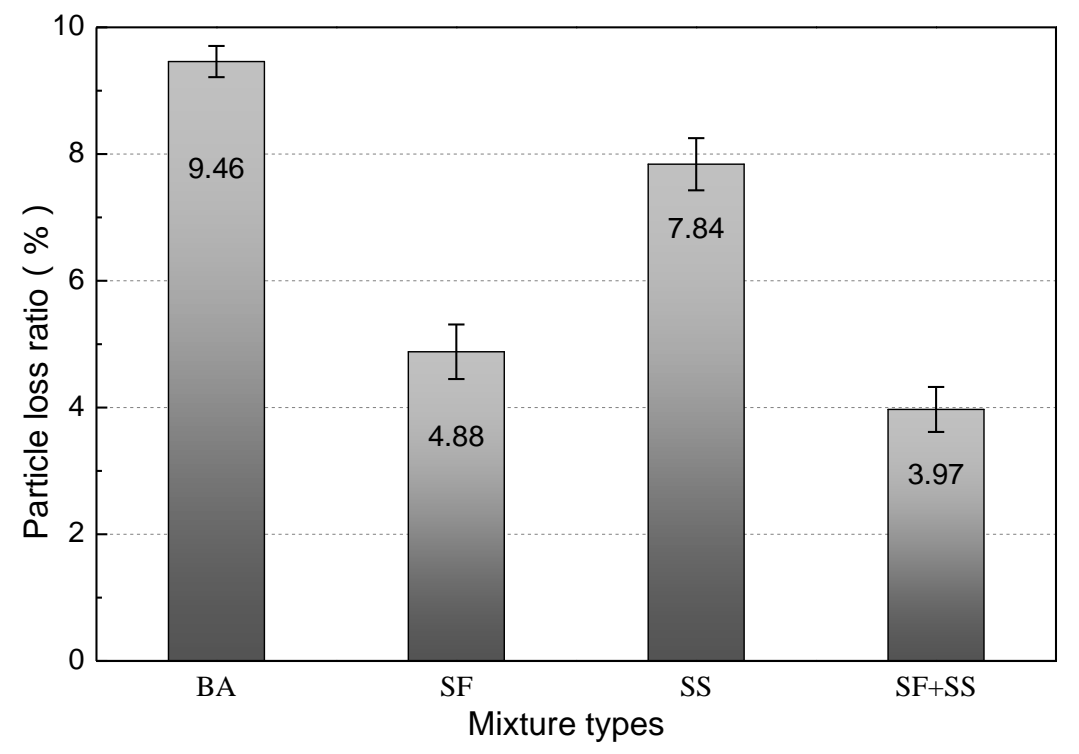

Figure 5. Particle loss resistances of different asphalt mixtures.

\subsection{Effect of Steel Fibers and Steel Slag on the Fracture Resistance of Asphalt Mixture}

The fracture energy and post-cracking energy of the four asphalt mixtures were shown in Figure 6. The fracture energy ranking of different mixtures was: SS + SF $>$ SS $>$ SF $>$ BA. Compared with basalt asphalt mixture, the fracture energy of SF, SS and SF + SS increased by $20.9 \%, 29.1 \%$, and $41.2 \%$ respectively. It indicates that the addition of steel fiber and steel slag can improve the fracture resistance of asphalt mixture. Steel slag has relatively high strength characteristics and good adhesion with asphalt binder, increasing the fracture strength of the mixture. Steel fiber increases the maximum fracture strain of the mixture, consuming more energy.

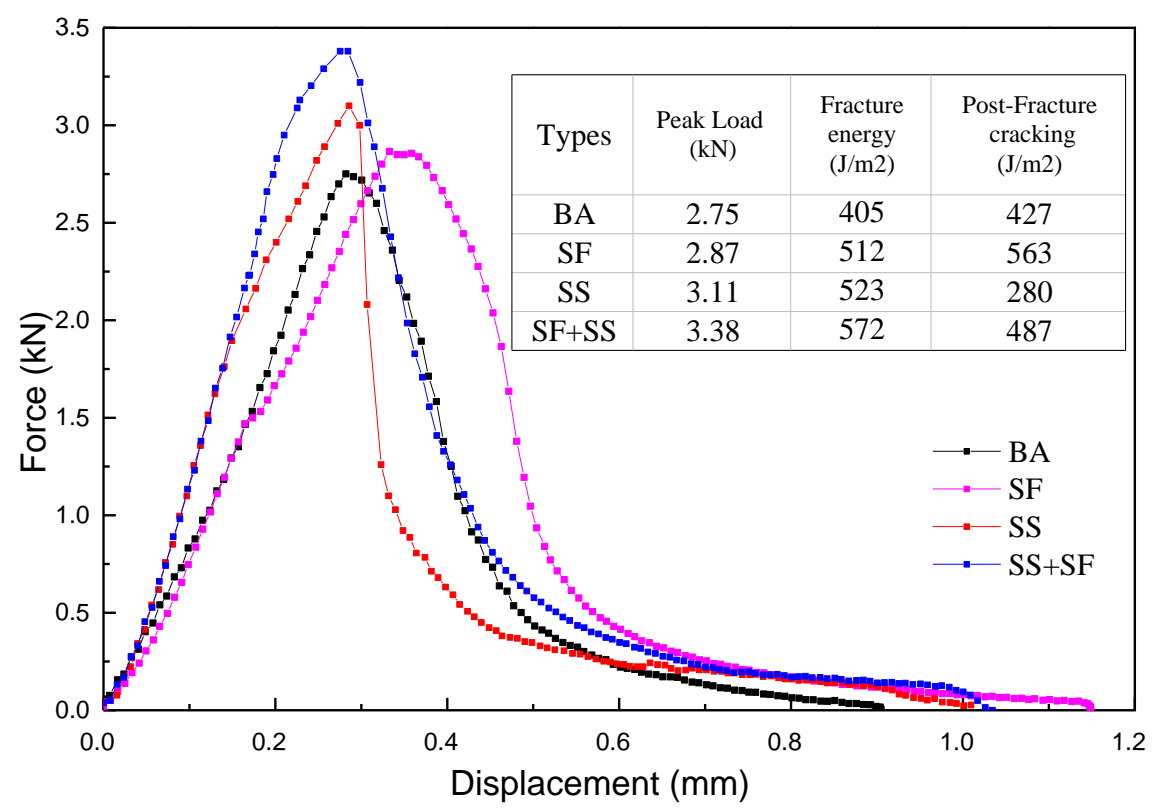

Figure 6. Fracture energy and post-cracking energy of different asphalt mixtures.

Figure 6 also shows that the addition of steel fiber can significantly improve the post-cracking energy of asphalt mixture, while adding steel slag decreased the post-cracking energy. It can be seen 
from Figure 6 that the post-cracking energy of SF and SF + SS increased by 31.9\% and 14.1\% compared with BA. The results demonstrated that the addition of steel fiber improves the toughness of asphalt mixture. The addition of steel slag reduces the toughness of asphalt mixture due to brittle damage of the asphalt mixture. The post-cracking energy of SS decreased by $34.4 \%$ compared with BA.

\subsection{Effect of Steel Fibers and Steel Slag on the Thermal Parameters of Asphalt Mixtures}

The thermal parameters of asphalt mixtures modified with steel fiber or/and steel slag were shown in Table 3. Compared with BA, the thermal conductivity and thermal diffusion of SF increased by $10.2 \%$ and $16.3 \%$ respectively, while the volumetric heat capacity decreased by $5.3 \%$. The thermal conductivity and thermal diffusion of SF + SS increased by $6.6 \%$ and $18.1 \%$ respectively, while the volumetric heat capacity decreased by $9.7 \%$. It means that steel fiber increased the thermal conductivity and thermal diffusion while decreased the volumetric heat capacity of asphalt mixture. Steel slag showed a reverse effect on the thermal parameters of asphalt mixture. The thermal conductivity and thermal diffusion of asphalt mixture decreased by $5.7 \%$ and $18.3 \%$ after adding steel slag in BA, and the volumetric heat capacity increased by $15.4 \%$. It can be concluded that the addition of steel fiber and steel slag will influence the thermal parameters of asphalt mixture. However, the thermal parameters of SS + SF showed the least difference from BA due to the opposite effects of steel fibers and steel slag.

Table 3. Thermal parameters of four kinds of asphalt mixtures.

\begin{tabular}{|c|c|c|c|}
\hline Mixture Type & $\begin{array}{l}\text { Thermal Conductivity } \\
(\mathrm{W} /(\mathrm{m} \cdot \mathrm{K}))\end{array}$ & $\begin{array}{l}\text { Thermal Diffusivity } \\
\qquad\left(\mathrm{mm}^{2} / \mathrm{s}\right)\end{array}$ & $\begin{array}{l}\text { Volumetric Heat Capacity } \\
\left(\mathrm{MJ} /\left(\mathrm{m}^{3} \cdot \mathrm{K}\right)\right)\end{array}$ \\
\hline $\mathrm{BA}$ & 1.521 & 0.717 & 2.121 \\
\hline SF & 1.676 & 0.834 & 2.009 \\
\hline SS & 1.434 & 0.586 & 2.447 \\
\hline $\mathrm{SF}+\mathrm{SS}$ & 1.529 & 0.692 & 2.210 \\
\hline
\end{tabular}

The material properties of the mixtures are the main reason for the changes in the thermal constants. As a kind of metal material, steel fibers possess good conductivity and diffusion of heat. Compared with basalt stone and asphalt, the conductivity and thermal diffusion of steel fibers were higher. While the heat capacity of steel fibers is lower than that of basalt and asphalt. In spite of containing some metal elements, a large number of tiny pores within steel slag obstruct the heat transfer and diffusion, decreasing the conductivity and thermal diffusion of the mixture. The tiny pores also have a heat storage capacity, which helps for the increase of the heat capacity of the mixture. Due to the opposite effects of steel fibers and steel slag, the thermal parameters of SS + SF will be strongly related to the ratio of steel fibers and steel slag.

\subsection{Effect of Steel Fibers and Steel Slag on the Heating and Cooling Characteristics of Asphalt Mixture}

The average surface temperature variations of different asphalt mixtures during induction heating and cooling were shown in Figure 7. As shown in Figure 7a, the average surface temperature of the samples increased linearly with heating time. The heating speed can be obtained by fitting line to get the slope of each curve. The induction heating speeds of the three mixtures (SS, SF, and SS + SF) were $0.15,1.11$ and $1.25^{\circ} \mathrm{C} / \mathrm{s}$ respectively. Steel slag containing a limited amount of metal oxides can be induction heated. Due to the limited amount of steel slag replacing mineral aggregates (only size 9.5-13.2 mm), the induction heating speed of SS mixture was quite low. In SS mixture, steel slag was the heat generating source and heat transferred from steel slag to mortar and other basalt aggregate was slow, leading to a more uneven heating in asphalt mixture. The steel fibers distributed quite uniformly in mortar of asphalt mixture, forming loop coil which can produce closed current. So, steel fibers can be heated very quickly under electromagnetic induction heating and SF showed a high heating speed. The heating speed of asphalt mixture containing both steel fibers and steel slag was the highest because of the co-heating effect of steel slag and steel fibers. The heating speed of SS + SF 
mixture was exactly the sum of the heating speeds of SS and SF, indicating that the composite of steel fibers and steel slag can enhance induction heating speed of asphalt mixture. It is expected that the induction heating speed of asphalt mixture can be further improved by increasing the proportion of steel slag replacing mineral aggregates.

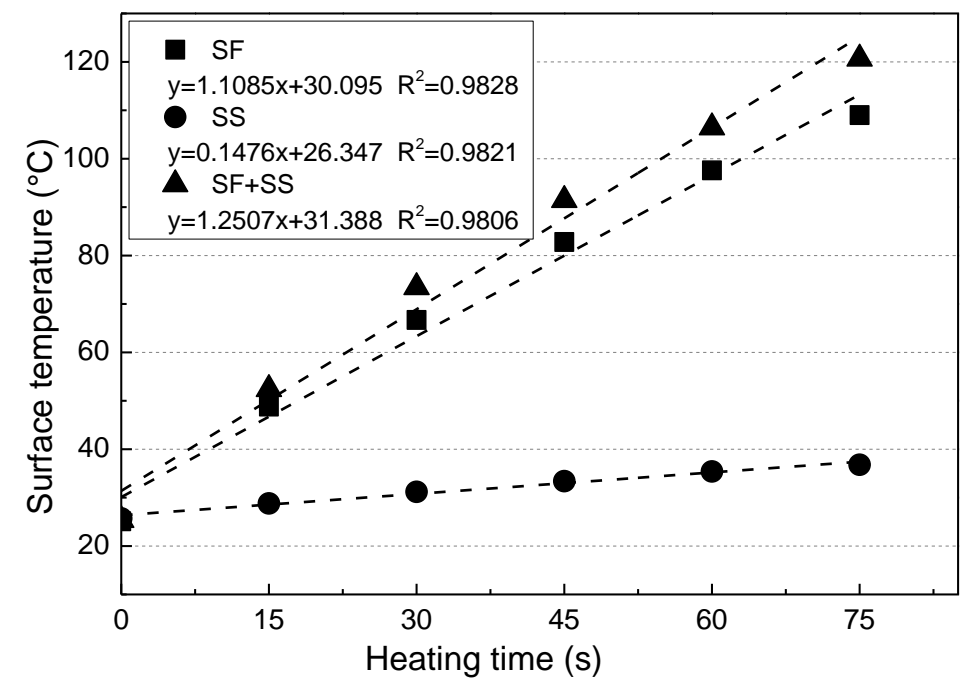

(a)

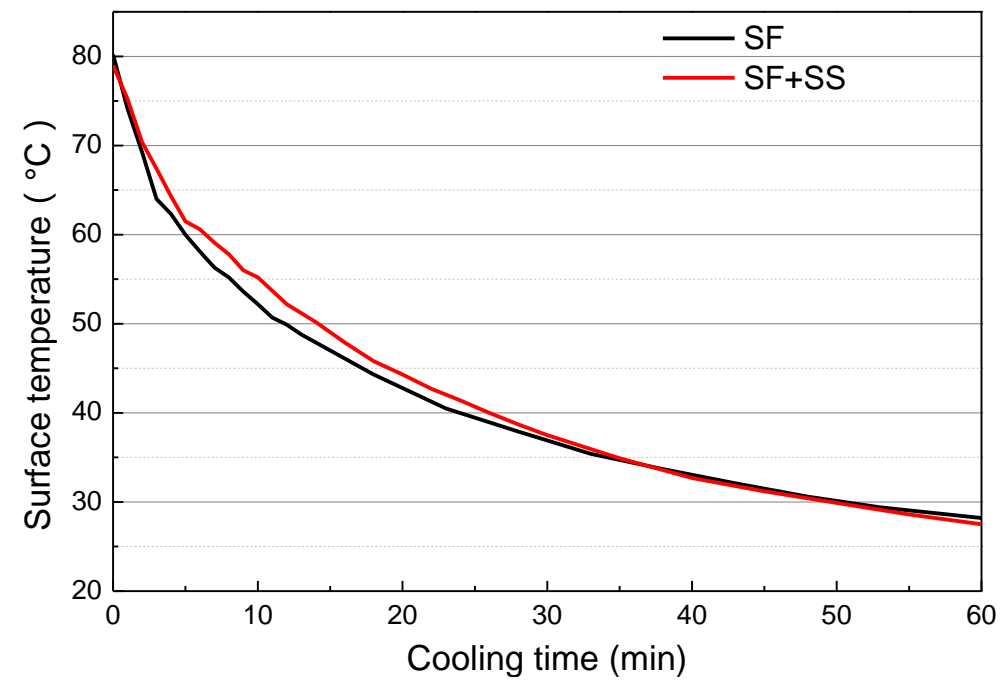

(b)

Figure 7. Temperature-versus-time curves of asphalt mixtures with induction heating. (a) During heating; (b) During cooling.

Crack healing occurs both during induction heating and cooling after heating. But the healing speed will gradually decrease due to the decrease of the temperature. Therefore, it is necessary to analyze the cooling process of different types of asphalt mixtures after induction heating. The heating of SS was quite slow and uneven, so the cooling curve of SS was not discussed in Figure $7 \mathrm{~b}$. The cooling curves of other two kinds of mixtures were shown in Figure $7 \mathrm{~b}$. The samples were heated to $80^{\circ} \mathrm{C}$ (average top surface temperature) and then placed in a constant temperature room to monitor the cooling process with an infrared camera. As shown in the cooling lines of the two asphalt mixtures, the temperature of SF decreased faster compared with SF + SS. The difference of cooling performance is mainly due to the performance of materials, because the initial temperature and the environment temperature are the same. It has been demonstrated from the thermal constants test that the thermal 
conductivity and thermal diffusion of SF are the highest, and the volumetric heat capacity of SS is highest. At the surface of the specimen heat transfers both to the lower part of the sample and to the air, thus the temperature decreased more rapidly than the inner positions. SF mixture lost heat more quickly as the material had higher thermal conductivity and thermal diffusion, which explained the difference of cooling rates of the two different kinds of mixtures.

\subsection{Effect of Steel Fibers and Steel Slag on the Induction Healing Efficiency of Asphalt Mixture}

The healing ratios of different types of asphalt mixtures at different surface heating temperatures were shown in Figure 8. In this experiment, the surface temperature of the sample was used as the heating temperature, while induction heating shows strong gradient heating characteristics. The temperature decreased with the depth of the sample, resulting in lower and lower healing ratio of the sample vertically. Besides, some stones were crushed during the fracture test, which also limited the healing efficiency of the sample. It can be seen in Figure 8 that the healing ratios of all mixtures increased gradually with the increase of the heating temperature, indicating that the temperature plays an important effect on the healing efficiency. The healing ratios of the three kinds of mixtures showed the same ranking at the different temperatures: $\mathrm{SS}+\mathrm{SF}>\mathrm{SF}>\mathrm{SS}$. This is mainly related to the differences of the heating characteristics of different mixtures.

Steel slag and steel fibers are the heating units in SS and SF asphalt mixtures respectively. In SS mixture, the mortar cannot be heated with induction heating and its temperature is much lower than steel slag. While the mortar containing steel fiber was directly heated in SF asphalt mixture. In SS + SF mixture, both the steel slag and the mortar containing steel fibers were induction heated, resulting in a more homogenous heating. Thus, the temperature of the mortar in different mixtures ranks: $\mathrm{SF}+\mathrm{SS}>\mathrm{SF}>\mathrm{SS}$. As temperature is the key factor controlling the healing ratio of asphalt mixture, the ranking of the healing ratios of different mixture was also $\mathrm{SF}+\mathrm{SS}>\mathrm{SF}>\mathrm{SS}$. It is concluded that the incorporation of steel fiber promotes the temperature increase of the mortar, contributing to higher healing ratio of the mixture at the same average temperature. SS + SF asphalt mixture has the highest healing ratio due to the more homogeneous temperature distribution which indicates a higher bulk temperature of the mixture.

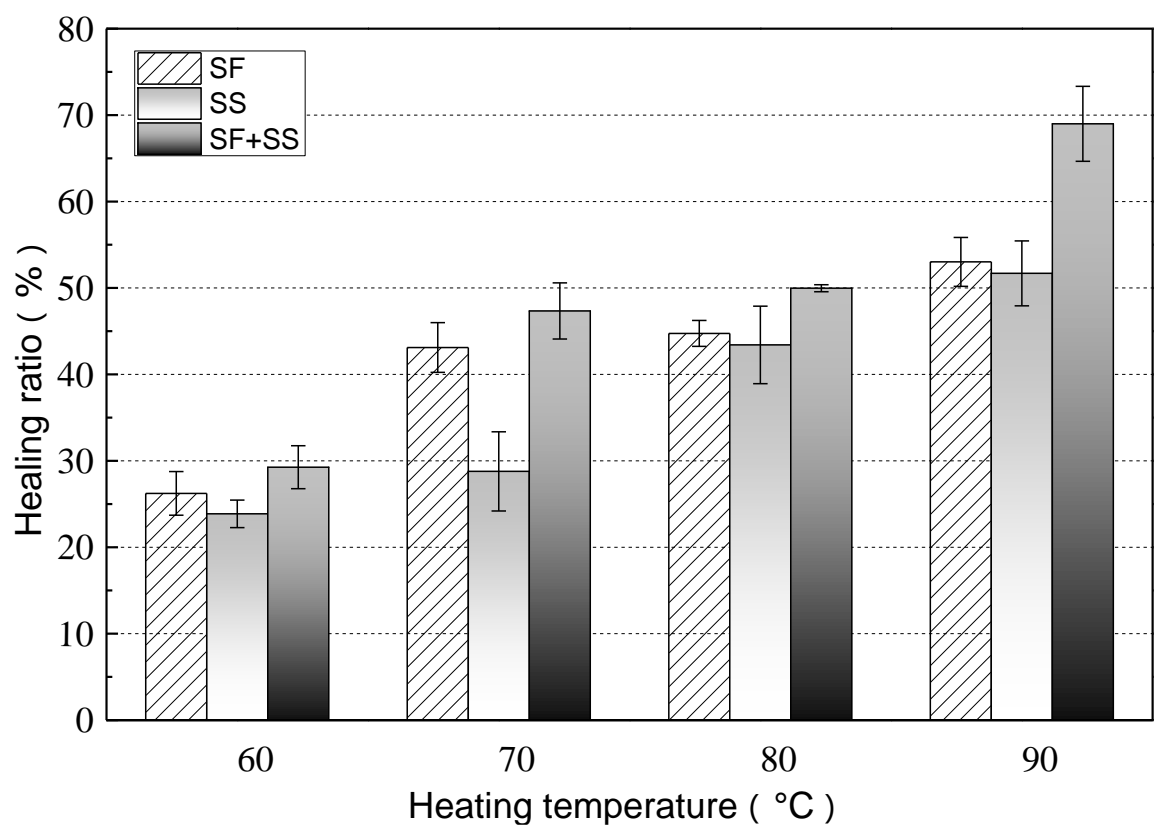

Figure 8. Healing ratio of asphalt mixture under different heating temperatures. 


\section{Conclusions}

In this paper, the water stability, mechanical properties, thermal constants, heating and healing properties of four asphalt mixtures BA, SF, SS and SF + SS were compared. The following conclusions can be drawn.

(1) The addition of steel slag and/or steel fibers improves the water stability of asphalt mixture. Marshall Stability and residual Marshall Stability ratio of asphalt mixture are increased by adding steel slag and/or steel fibers.

(2) The addition of steel slag and/or steel fiber can improve the particle loss resistance and the fracture energy of asphalt mixture. Steel fiber increases the toughness of asphalt mixture, while steel slag reduce the toughness of the mixture.

(3) Steel fibers increase the thermal conductivity and thermal diffusion of asphalt mixture, and steel slag shows a reverse effect. The volumetric heat capacity of steel slag mixture is higher than plain and steel fiber asphalt mixtures.

(4) The composite of steel fibers and steel slag can enhance the induction heating speed of asphalt mixture. The heating speed ranking of different asphalt mixtures is SF $+\mathrm{SS}>\mathrm{SF}>\mathrm{SS}$. The cooling rate of the SF and SF + SS mixture show different ranking SF $>$ SF + SS, which can be explained according to the thermal constants of the mixtures.

(5) The composite of steel fibers and steel slag can increase the heating homogeneity and thus enhance the induction healing ratio of asphalt mixture. Due to different heating units in different asphalt mixtures, the healing ratio ranking of the three mixtures is $\mathrm{SF}+\mathrm{SS}>\mathrm{SF}>\mathrm{SS}$ at the same surface temperature.

Acknowledgments: This research was supported by the Natural Science Foundation of China (No. 51508433 and No. 51778515), the Open Fund of the Key Laboratory of Highway Engineering in Special Regions of Ministry of Education of China, Chang'an University (No. 310821161105), the Open Fund of the Key Laboratory of Road Structure and Material of Ministry of Transport (Changsha University of Science \& Technology, No. kfj150302), and the Scientific Research Foundation for Returned Overseas Chinese Scholars, State Education Ministry.

Author Contributions: Quantao Liu, Yihan Sun and Shaopeng Wu conceived and designed the experiments; Bin Li performed the experiments; Erik Schlangen analyzed the data; Yihan Sun contributed reagents/materials/analysis tools; Quantao Liu and Bin Li wrote the paper.

Conflicts of Interest: The authors declare no conflict of interest.

\section{References}

1. Tabaković, A.; Schuyffel, L.; Karač, A.; Schlangen, E. An evaluation of the efficiency of compartmented alginate fibres encapsulating a rejuvenator as an asphalt pavement healing system. Appl. Sci. 2017, 7, 647. [CrossRef]

2. Little, D.; Bhasin, A. Exploring mechanisms of healing in asphalt mixtures and quantifying its impact. In Self Healing Materials an Alternative Approach to 20 Centuries of Materials Science; Springer Series in Materials Science; Springer: Berlin, Germany, 2007; pp. 205-218.

3. García, Á. Self-healing of open cracks in asphalt mastic. Fuel 2012, 93, 264-272. [CrossRef]

4. García, Á.; Schlangen, E.; van de Ven, M.; Liu, Q. Electrical conductivity of asphalt mortar containing conductive fibers and fillers, Constr. Build. Mater. 2009, 23, 3175-3181. [CrossRef]

5. Gómez-Meijide, B.; Ajam, H.; Lastra-González, P.; García, Á. Effect of air voids content on asphalt self-healing via induction and infrared heating. Constr. Build. Mater. 2016, 126, 957-966. [CrossRef]

6. Liu, Q.; Schlangen, E.; García, Á.; van de Ven, M. Induction heating of electrically conductive porous asphalt concrete. Constr. Build. Mater. 2010, 24, 1207-1213. [CrossRef]

7. Liu, Q.; Wu, S.; Schlangen, E. Induction heating of asphalt mastic for crack control. Constr. Build. Mater. 2013, 41, 345-351. [CrossRef]

8. Yang, J.M.; Kim, J.K.; Yoo, D.Y. Effects of amorphous metallic fibers on the properties of asphalt concrete. Constr. Build. Mater. 2016, 128, 176-184. [CrossRef] 
9. Pamulapati, Y.; Elseifi, M.A.; Cooper, S.B.; Mohammad, L.N.; Elbagalati, O. Evaluation of self-healing of asphalt concrete through induction heating and metallic fibers. Constr. Build. Mater. 2017, 146, 66-75. [CrossRef]

10. García, Á.; Schlangen, E.; van de Ven, M.; van Vliet, D. Induction heating of mastic containing conductive fibers and fillers. Mater Struct. 2011, 44, 499-508. [CrossRef]

11. Sun, Y.; Wu, S.; Liu, Q.; Zeng, W.; Chen, Z.; Ye, Q.; Pan, P. Self-healing performance of asphalt mixtures through heating fibers or aggregate. Constr. Build. Mater. 2017, 150, 673-680. [CrossRef]

12. Liu, Q.; Schlangen, E.; van de Ven, M.; van Bochove, G.; Montfort, J. Evaluation of the induction healing effect of porous asphalt concrete through four point bending fatigue test. Constr. Build. Mater. 2012, 29, 403-409. [CrossRef]

13. Dai, Q.; Wang, Z.; Mohd Hasan, M.R. Investigation of induction healing effects on electrically conductive asphalt mastic and asphalt concrete beams through fracture-healing tests. Constr. Build. Mater. 2013, 49, 729-737. [CrossRef]

14. Menozzi, A.; García, Á.; Partl, M.N.; Tebaldi, G.; Schuetz, P. Induction healing of fatigue damage in asphalt test samples. Constr. Build. Mater. 2015, 74, 162-168. [CrossRef]

15. He, L.; Zhao, L.; Ling, T.; Ma, Y.; Liu, Q. Research on induction heating activated self-healing of cracks in dense graded asphalt mixture. China J. Highw. Transp. 2017, 30, 17-24.

16. Liu, Q. Induction Healing of Porous Asphalt Concrete. Ph.D. Thesis, Delft University of Technology, Delft, The Netherlands, 2012.

17. Norambuena-Contreras, J.; García, Á. Self-healing of asphalt mixture by microwave and induction heating. Master. Des. 2016, 106, 404-414. [CrossRef]

18. García, Á.; Norambuena-Contreras, J.; Partl, M.N. Experimental evaluation of dense asphalt concrete properties for induction heating purposes. Constr. Build. Mater. 2013, 46, 48-54. [CrossRef]

19. García, Á.; Bueno, M.; Norambuena-Contreras, J.; Partl, M.N. Induction healing of dense asphalt concrete. Constr. Build. Mater. 2013, 49, 1-7. [CrossRef]

20. Ministry of Transport of the People's Republic of China. JTG E20-2011. Standard Test Methods of Asphalt and Asphalt Mixtures for Highway Engineering; Research Institute of Highway (Ministry of Transportation; China): Beijing, China, 2011; Volume 1, pp. 204-214.

21. Li, X.-J.; Marasteanu, M.O. Using Semi Circular Bending Test to Evaluate Low Temperature Fracture Resistance for Asphalt Concrete. Exp. Mech. 2010, 5, 867-876. [CrossRef]

22. Roque, R.; George, L. Development and Evaluation of a Simplified Superpave IDT Testing System for Implementation in Mix Design and Control; Final Report: FDOT-BD545-38; Florida Department of Transportation: Tallahassee, FL, USA, 2008.

23. RILEM TV-50 FMC. Determination of the fracture energy of mortar and concrete by means of three-point bend tests on notched beams. Mater. Struct. 1985, 18, 285-290.

24. Rossi, C.; Teltayev, B.; Angelico, R. Adhesion Promoters in Bituminous Road Materials: A Review. Appl. Sci. 2017, 7, 524. [CrossRef]

25. Sheng, Y.; Li, H.; Guo, P.; Zhao, G.; Chen, H.; Xiong, R. Effect of Fibers on Mixture Design of Stone Matrix Asphalt. Appl. Sci. 2017, 7, 297. [CrossRef]

26. Xie, J.; Wu, S.; Lin, J.; Cai, J.; Chen, Z.; Wei, W. Recycling of basic oxygen furnace slag in asphalt mixture: Material characterization \& moisture damage investigation. Constr. Build. Mater. 2012, 36, 467-474.

(C) 2017 by the authors. Licensee MDPI, Basel, Switzerland. This article is an open access article distributed under the terms and conditions of the Creative Commons Attribution (CC BY) license (http://creativecommons.org/licenses/by/4.0/). 